\title{
PENGARUH INFORMASI AKUNTANSI DALAM KEBIJAKAN PENGAMBILAN KEPUTUSAN KEUANGAN PT. INCIPNA INDONESIA MAKASSAR
}

\author{
Faidul Adziem ${ }^{1}$ Idra Wahyuni $^{2}$ Sarman $^{3}$ \\ Universitas Muhammadiyah Makassar \\ e-mail : idrawahyuni@unismuh.ac.id
}

\begin{abstract}
Research aims to determine the influence of accounting information in the financial decision making policy of PT. Incipna Indonesia Makassar. The object of the study's financial management income, the instrument in the study was through kuesiner to the parties concerned. The research also collects the relevant documents and supports the discussion of the research. The testing techniques used are simple linear regression. The results found that the accounting information was influential in the financial decision making policy of PT. Incipna Indonesia Makassar. In formulating financial policies, consider the vision, mission, objectives, and objectives so that each policy is made.
\end{abstract}

Keywords: accounting information, financial and company policies

\begin{abstract}
Abstrak
Penelitian ini bertujuan untuk mengetahui pengaruh informasi akuntansi dalam kebijakan pengambilan keputusan keuangan pt. Incipna indonesia makassar. Objek dari penelitian ini pendapatan pengelolaan keuangan, instrumen dalam penelitian ini adalah melalui kuesiner kepada pihak-pihak yang bersangkutan. Penelitian juga mengumpulkan dokumen-dokumen yang relavan dan mendukung pembahasan penelitian. Teknik pengujian yang digunakan adalah regresi linier sederhana. Hasil penelitian menemukan bahwa informasi akuntansi berpengaruh dalam kebijakan pengambilan keputusan keuangan pt. Incipna Indonesia Makassar. Dalam merumuskan kebijakan keuangan, jga mempertimbangkan visi, misi, sasaran, dan tujuan sehingga setiap kebijakan yang di buat.
\end{abstract}

Kata kunci: informasi akuntansi, kebijakan keuangan dan perusahan 


\section{PENDAHULUAN}

Pada masa perkembangan ilmu pengetahuan dan teknologi sekarang ini sangatlah diperlukan informasi-informasi yang menunjang bagi kemajuan dan kepentingan organisasi, baik organisasi sektor privat maupun sektor publik. Menurut Davis dalam Kadir (2003:28), informasi adalah data yang telah diolah menjadi sebuah bentuk yang berarti bagi penerimanya dan bermanfaat bagi pengambilan keputusan saat ini atau saat mendatang. Salah satu informasi yang selalu dibutuhkan oleh setiap organisasi adalah informasi akuntansi. Saat Ini Di Indonesia, Informasi Akuntansi Yang Disajikan Dalam Laporan Keuangan Mengacu PadaPT. Incipna Indonesia Makassar Standar Akuntansi Informasi Yang Bermanfaat Bagi Para Pengguna Dalam Menilai Akuntabilitas Dan Membuat Keputusan, Baik Keputusan Ekonomi, Sosial, Maupun Politik. Pengambilan Keputusan Dalam Pemerintahan Tentunya Didasarkan Atas Informasi-Informasi Relevan Yang Diperoleh PT. Incipna Indonesia Begitu Pula Dengan Kebijakan Keuangan yang diambil oleh PT.Incipna Indonesia makassar yang seharusnya didasarkan atas informasi akuntansi atau laporan keuangan yang telah dibuat oleh PT. Incipna Indonesia bersangkutan.

Suatu keputusan tidak akan memiliki tingkat keakuratan yang baik jika tidak didukung berbagai informasi yang ada. Berbagai informasi yang diterima akan dianalisis oleh pihak manajemen untuk menghasilkan beberapa rekomendasi keputusan yang bersifat alternatif, yang salah satu diantaranya akan diambil sebagai keputusan yang terbaik. Menurut Hendriksen dalam Arief (2010), "pengambilan sebuah keputusan terkadang dianggap sebagai sebuah perjudian karena setiap individu/orang yang melakukan pengambilan keputusan akan dihadapkan pada sebuah resiko besar nantinya." Individu yang siap menghadapi resiko disebut dengan "penjudi", tetapi terkadang tidak semua orang berani mengambil resiko, bahkan cenderung menghindar dari sebuah resiko yang akan dihadapi.

\section{TINJAUAN PUSTAKA}

\section{Laporan Keuangan}

Menurut PSAP No.1 (2010), laporan keuangan merupakan laporan yang terstruktur mengenai posisi keuangan dan transaksitransaksi yang dilakukan oleh suatu entitas pelaporan. Selain itu menurut Soemarsono (2004:34), laporan keuangan adalah laporan yang dirancang untuk para pembuat keputusan, terutama pihak diluar perusahaan, mengenai posisi keuangan dan hasil usaha perusahaan

\section{Kualitas Informasi}

Menurut Nugroho Widjajanto (2004) mendefinisinakan kualitas informasi dapat dikatakan berkualitas bila informasi tersebut mengandung ketidak pastian paling rendah, akan tetapi informasi tidak dapat terbebas sama sekali dari unsur ketidakpastian. Oleh karena itu diperlukan perbandingan antara data memperoleh informasi dengan manfaaat yang diperoleh dengan andanya informasi itu sendiri. Dengan kata lain informasi baru layak disiapkan jika, biayanya lebih rendah daripada tambahan pendapatan nyata yang dihasilkan dari adanya informasi itu

\section{Faktor-Faktor Yang Mempengaruhi Kualitas Informasi Laporan Keuangan:}

Adapun faktor faktor yang mempengaruhi kualitas informasi laporan keuangan terdiri dari sumber daya manusia dan sistem pengendalian intern. Dapat di jabarkan sebagai berikut:

\section{a. Sumber Daya Manusia}

Dalam pengolahan keuangan yang baik harus memiliki sumber daya manusia yang kompeten, yang didukung dengan latar belakang pendidikan akuntansi, mengikuti pendidikan dan pelatihan, dan mempunyai pengalaman dibidang keuangan. Hal tersebut diperlukan untuk menerapkan sistem akuntansi yang ada. Sumber daya manusia yang kompeten tersebut akan mampu memahami logika akuntansi dengan baik.

b. Sistem Pengendalian Intern 
Peraturan Pemerintah nomor 60 tahun 2008 tentang Sistem Pengendalian Intern Pemerintah (SPIP) mendefinisikan pengendalian intern adalah proses yang integral pada tindakan dan kegiatan yang dilakukan secara terus menerus oleh pimpinan dan seluruh pegawai untuk memberikan keyakinan memadai atas tercapainya tujuan organisasi melalui kegiatan yang efektif dan efesien, keandalan pelaporan keuangan, pengamanan aset Negara, dan ketaatan.

\section{METODE}

\section{Pendekatan Penelitian}

Pendekatan yang digunakan dalam penelitian ini adalah pendekatan kuantitatif dengan ilmiah yaitu berfikit untuk memecahkan masalah secara sistematis, empiris, dan terkontrol yang dengan angka-angka. Penetapan lokasi dari suatu penelitian sangat penting dalam rangka pertanggungjawaban data yang diperoleh. Oleh karena itu, lokasi penelitian yang menjadi suatu populasi dan sampel dalam penelitian adalah Lokasi yang dipilih sebagai tempat penelitian yaitu PT.Incipna Indonesia yang beralamat JL. Abubakar lamboko no.192. Sedangkan jangka waktu penelitian hingga perumpaman diperkirakan 2 (dua) bulan pada tahun 2016 Adapun jenis data yang digunakan dalam penelitian ini adalah data kualitatif dan kuantitatof, sedangkan Sumber data yang diperoleh dalam penelitian ini adalah sumber sekunder.

\section{Metode Analisis Data}

Adapun metode analisis data yang digunakan untuk menguji hipotesis adalah menggunakan analisis regresi dengan bantuan perangkat lunak SPSS. Setelah data-data terkumpul, maka langkah selanjutnya dilakukan analisis data terdiri dari uji deskriptife statistic, uji kualitas data, uji asumsi klasik dan uji hipotesis. Pengujian hipotesis dilakukan dengan menggunakan persamaan regresi sederhana, uji t, uji determinasi, dan uji statistik F. Berikut ini model persamaan regresi sederhanadapat dijabarkan sebagai berikut:

$$
\mathrm{Y}=\mathrm{a}+\mathrm{bx}
$$

Dimana:

$\mathrm{y} \quad=$ Pengendalian Modal Kerja (Variabel Dependen)

$a=$ konstanta

$\mathrm{bx}=$ Sistem Informasi Akuntansi (Variabel Independen)

\section{HASIL DAN PEMBAHASAN}

\section{Hasil}

a. Uji validitas dan realibilitas variable $\mathrm{X}$ informasi akuntansi.

Tabel 1. Variabel X informasi akuntansi Tabe 1

\begin{tabular}{ccccc}
\hline Informasi akuntansi $\mathbf{X}$ & validitas & Keterangan & Realibitas & Reliable \\
\hline $\mathbf{X 1}$ & 12.897 & VALID & 0,725 & 0,6 \\
\hline $\mathbf{X 2}$ & 12.436 & VALID & 0,725 & 0,6 \\
\hline $\mathbf{X 3}$ & 13.090 & VALID & 0,725 & 0,6 \\
\hline $\mathbf{X} 4$ & 12.897 & VALID & 0,725 & 0,6 \\
\hline $\mathbf{X 5}$ & 12.897 & VALID & 0,725 & 0,6 \\
\hline $\mathbf{X 6}$ & 12.897 & VALID & 0,725 & 0,6 \\
\hline $\mathbf{X} 7$ & 12.897 & VALID & 0,725 & 0,6 \\
\hline $\mathbf{X 8}$ & 12.897 & VALID & 0,725 & 0,6 \\
\hline $\mathbf{X 9}$ & 12.897 & VALID & 0,725 & 0,6 \\
\hline $\mathbf{X 1 0}$ & 12.897 & VALID & 0,725 & 0,6 \\
\hline $\mathbf{X 1 1}$ & 10.436 & VALID & 0,725 & 0,6 \\
\hline $\mathbf{X 1 2}$ & 9.756 & VALID & 0,725 & 0,6 \\
\hline $\mathbf{X 1 3}$ & 9.756 & VALID & 0,725 & 0,6 \\
\hline $\mathbf{X 1 4}$ & 9.756 & VALID & 0725 & 0,6 \\
\hline
\end{tabular}

Sumber: hasil olahan data primer 2016 
Berdasarkan tabel 1 di aatas dapat menyatakan bahwa setiap butir pertanyaan yang di gunakan untuk mengukur variabel informasi akuntansi sudah valid karna semua nilai yang terterah dalam 1 bernilai lebih besar dari 0,2. Hal ini menunjukan bahwa setiap pertanyaan mengenai informasi akuntansi dapat di pahami oleh responden sehingga jawaban yang diberikan dapat digunakan untuk mengukur variabel $\mathrm{X}$ atau valid.
Dilihat dari kolom 3 realibitas variabel informasi akuntansi adalah 0,725 sehingga dapat di nyatakan relibitas karna nilainya lebih besar sari 0,6. Hal ini menunjukkan bahwa jawaban dari hasil pernyatan mengenai informasi akuntansi yang terdapat di konsiner dapat di kategorikan sudah konsisten sehingga dapat di uji.

b. Uji validitas dan realibilitas variable $\mathrm{Y}$ keputusan keuangan

Tabel 2. Validitas Y keputusan keuangan

\begin{tabular}{ccccc}
\hline Keputusan keuangan Y & Validitas & Keterangan & Realibitas & Reliabel \\
\hline Y1 & 47.436 & VALID & 0,820 & 0,6 \\
\hline Y2 & 46.731 & VALID & 0,820 & 0,6 \\
\hline Y3 & 47.436 & VALID & 0,820 & 0,6 \\
\hline Y4 & 46.090 & VALID & 0,820 & 0,6 \\
\hline Y5 & 46.090 & VALID & 0,820 & 0,6 \\
\hline Y6 & 46.090 & VALID & 0,820 & 0,6 \\
\hline Y7 & 41.974 & VALID & 0820 & 0,6 \\
\hline Y8 & 41.974 & VALID & 0,82 & 0,6 \\
\hline Y9 & 44.731 & VALID & 0.820 & 0,6 \\
\hline Y10 & 44.731 & VALID & 0,820 & 0,6 \\
\hline Y11 & 34.359 & VALID & 0,820 & 0,6 \\
\hline Y12 & 43.359 & VALID & 0,820 & 0,6 \\
\hline Y13 & 44.731 & VALID & 0,820 & 0,6 \\
\hline Y14 & 44.731 & & 0,820 & 0,6
\end{tabular}

Sumber: hasil data diolah primer 2016

Berdasarkan tabel validitas variabel keputusan keuangan di atas dapat di nyatakan bahwa setiap butir pernyatan yang digunakan untuk mengukur variabel keputusan keungan sudah valid karna semua nilai yang tertera pada kolom 1 bernilai lebih besar dari 0,2. hal ini menunjukkan bahwa setiap pertanyaan mengenai keputusan keungan dapat dipahami oleh responden sehingga jawaban yang digunakan untuk mengukur variabel $\mathrm{Y}$ keputusan keungan. Dilihat dari kolom 3 reabilitasvariabel keputusan keungan adalah 0,820 sehingga dapat di nyatakan riabelitas karna nilainya lebih besar dari 0,6 . Hal ini menunjukkan bahwa jawaban dari hasil pernyatan mengenai keputusan keungan yang terdapat di kuensiner dapat di kategorikan sudah konsisten sehingga dapat di uji.

\section{Pengujian hipotesis}

Tabel 3. Hasil huji T

\begin{tabular}{|c|c|c|c|c|c|}
\hline \multirow{2}{*}{ Model } & \multicolumn{2}{|c|}{ Unstandardized Coefficients } & $\begin{array}{l}\text { Standardized } \\
\text { Coefficients }\end{array}$ & \multirow[t]{2}{*}{$\mathrm{t}$} & \multirow{2}{*}{ Sig. } \\
\hline & B & Std. Error & Beta & & \\
\hline \multirow{2}{*}{1 (Constant) $\mathrm{x} 1$} & 12.203 & 10.382 & & 7.533 & .000 \\
\hline & .346 & .152 & -.279 & 2.963 & .012 \\
\hline \multicolumn{6}{|c|}{$\mathrm{Y}=12,203+0,346 \mathrm{X}$} \\
\hline
\end{tabular}


Dasar pengambilan keputusan adalah jika jika nilai sig $<0,05$ atau $\mathrm{T}$ hitung $>\mathrm{T}$ tabel maka terdapat pengaruh variable $\mathrm{X}$ terhadap variable Y maka Hipotesis diterima. Berarti variabel independen (informasi akuntansi) berpengaruh singnifikan terhadap variabel kebijakan pengambilan keputusan keuangan.

Berdasarkan hasil uji yang telah dilakukan untuk menguji informasi akuntansi padapt. Incipna indonesia Makassar menunujukan bahwa informasi Akuntansi dan keputusan keuangan perusahan sudah efektif. Hal ini sesuai dengan perolehan nilai rata-rata variabel Informasi Akuntansi (X) sebesar 0.839 dan keputusan keuangan (Y) sebesar 0,810 yang berarti Informasi Akuntansi dan keputusan keuangan "Efektif". Jika dikaitkan dengan hasil kuesioner sebagaimana telah dijelaskan di atas, maka dapat dikatakan bahwa informasi akuntansi dan keputusan keuangan PT. Incipna indonesia makassar sudah baik.

Hasil penelitian yang menunjukkan adanya hubungan antara variabel $\mathrm{X}$ informasi akuntansi dan variabel $Y$ keputusan keuangan pada sektor perusahan yang pada penelitian mengambil objek PT. Incipna Indonesia Makassar menegaskan peran penting informasi akuntansi. Meskipun penelitian ini menggunakan objek yang berbeda namun hasil dari penelitian mengonfirmasi hasil penelitian sebelumnya yang membahas mengenai peran informasi akuntansi dalam pengambilan kebijakan pada sektor privat. (Rusmanto, 2006; arief, 2010)

PT. Incipna indonesia makassar merupakan salah satu perusahan yang dalam kegiatan operasional sehari-hari sangat memperhatikan informasi akuntansi yang berlaku, terlebih berlaku pada pelaksanaan pengaruh informasi akuntuansi yang di jalankan oleh perusahan pt. Incopna indonesia makassar mempunyai pandangan bahwa fungsi informasi yang di perlakukan oleh perusahan adalah sebagai alat untuk mempermuda pimpinan perusahan dalam melakukan aktivitas perusahan dan di manfaatkan menejemen dalam pengambilan keputusan, terutama berkaitan dengan keputusan dalam aktivitas pengambilan keuanagan. Informasi akuntansi yang di terapkan pada pt. Incipna Indonesia Makassar di lakukan dengan proses manual dan komputerisasi yang berterap sesui keadaan serta perkembangan perusahan.

Pelaksanaan informasi akuntansi dalam kebijakan pengambilan keputusan keuangan pt. Incipna Indonesia Makassar tidak lepas dari unsusr - unsur informasi akuntansi yang ada. Peran informasi akuntansi dalam kebijakan pengambilan keputusan keuangan dalam perusahan mampu menopang perencanaan dan pengendalian perusahan. Membutukan informasi akuntansi selain informasi politik, sosial dan informasi lainya. Penelitian ini mempertegas peran informasi akuntansi sebagai dasar pengambilan kebijakan. Penelitian rusmianto (2006), dewi, dan muchyi (2009) serta arief (2010) lebih berfokus pada pengambilan keputusan pengguna produk/jasa sebuah perusahan/layanan publik namun di anggap penting junga para pengambilan kebijakan perusahan untuk menjalankan roda organisasi.

Struktur oganisasi pada perusahaan sangatlah penting arti dan peranannya, karena keberadaannya memberikan suatu gambaran tentang hierarki setiap unit kerja dalam perusahaan sehingga setiap personil atau unit kerja akan lebih mudah memahami dan melaksanakan tugas dan tanggung jawabnya. Dalam stuktur organisasi telah ditekankan tentang garis koordinasi atau tanggung jawab dari masing-masing personil atau unit kerja dengan tujuan untuk memperlancar berbagai aktifitas perusahaan dalam mencapai tujuannya. Penyusunan struktur organisasi haruslah sesuai dengan operasional perusahaan bahkan cenderung menggambarkan ruang lingkup kegiatan usaha pada umumnya. Dengan demikian melalui struktur organisasi dapat mengetahui secara garis besar pelaksanaan kegiatan operasional suatu perusahaan, meskipun sebenarnya tidak mengetahuinya secara rincih.

Struktur organisasi merupakan susunan bagian atau unit kerja dalam sebuah organisasi yang mencerminkan tugas-tugas yang diemban 
masing-masing personil. Struktur organisasi cukup penting dalam mendukung kelancaran aktivitas sebuah organisasi, karena semua pihak telah ditentukan tugas dan tanggung jawabnya sehingga tidak terjadi overlapping

\section{KESIMPULAN DAN SARAN}

\section{Kesimpulan}

Berdasarkan uraian dan analisis yang telah di kemukakan dari bab-bab dahulu maka, bab terakhir ini penulis akan memaparkan kesimpulannya adalah Dasar pengambilan keputusan adalah jika jika nilai sig $<0,05$ atau $\mathrm{T}$ hitung $>\mathrm{T}$ tabel maka terdapat pengaruh variable $\mathrm{X}$ terhadap variable $\mathrm{Y}$ maka Hipotesis diterima. Berarti variabel independen (informasi akuntansi) berpengaruh singnifikan terhadap variabel kebijakan pengambilan keputusan keuangan sudah sangat baik.

\section{Saran}

Saran bagi intansi terkait, terbuktinya sistem informasi akuntansi berpengaruh terhadap pengambilan keputusan keuangan maka kepada pt. Incipna Indonesia Makassar untuk lebih menjaga pelaksanan informasi akuntansi dapat di terapkan dengan baik. Bagi peneliti selanjutnya yang ingin melakukan penelitian sejenis agar lebih cermat memperhatikan opsiopsi fiskal yang mana yang dapat di timpuh oleh objek penelitian dalam pengaruh informasi akuntansi dalam kebijakan pengambilan keputusan keuangan.

\section{REFERENSI}

Abdullah S. Sistem Pengendalian Internal Pemerintah: Perlukah? Atau, Mengapa? (online) (http://syukriy.wordpress.com/2008/10/1 9/sistem-pengendalianinternalpemerintah-perlukah-atau-mengapa/), diakses 2015.

Abdullah S. Daya Serap Anggaran Rendah Masalah Desentralisasi Fiskal. (online) (http://syukriy.wordpress.com/2009/01/2 1/daya-anggaranrendah

masalahdesentralisasi-fiskal-daerah), diakses 18 januari 2015.

Elim J, Safral M. 2009. Lingkungan Pengendalian. Jakarta: Pusdiklatwas BPKP. Haryanto, Arifuddin, Sahmuddin. 2007. Akuntansi Sektor PublikSemarang: Badan Penerbit Universitas Diponegoro.

Hasmah R. Menyongsong penerapan SPIP: Menuju tata kelola pemerintah yang lebih baik. (online) (http://www.bappenas.go.id/blog/?p=29), diakses18 januari 2012.

Kabupaten Pinrang Dalam Angka 2009. 2009. Muna: Badan Pusat Statistik Kabupaten Pinrang.

Mamesah, DJ. 1995. Sistem Administrasi Keuangan Daerah. Jakarta: Gramedia Pustaka Utama.Pedoman Pengelolaan Keuangan Daerah. 2006. Jakarta Penerbit CV TamitaUtama.

Soeseno K. 2009. Pedoman Teknis Umum Penyelenggaraan Sistem Pengendalian Intern Pemerintah. Jakarta: Badan Pengawasan Keuangandan Pembangunan.

Suparmoko M. 2002 Ekonomi Publik untuk Keuangan \& Pembangunan Daerah. Yogyakarta: Penerbit Andi.

Yuwono S, Utomo DC, Zein S, R Azrafiani A. 2008. Memahami APBD dan Permasalahannya (Panduan Pengelolaan Keuangan Daerah). Malang: Bayumedia Pulishing.

Widayadi D. 2008. Abstraksi Peraturan Pemerintah Republik Indonesia Nomor 60 Tahun 2008 tentang Sistem Pengendalian Intern Pemerintah \& PeranBPKP. Makassar: Perwakilan BPKP Provinsi Sulawesi Selatan. 